\title{
Rearticulating the Concept of Experience, Rethinking the
}

\section{Demands of Deconstruction}

\author{
Steven Gormley \\ University of Essex
}

\begin{abstract}
A principal aim of this paper is to convince friends and critics of deconstruction that they have overlooked two crucial aspects of Derrida's work, namely, his rearticulation of the concept of experience and his account of the experience of undecidability as an ordeal. This is important because sensitivity to Derrida's emphasis on the ordeal of undecidability and his rearticulation of the concept of experience - a rearticulation that is already underway in his early engagement with Husserl and continued in later work—necessitates a rethinking of what the 'experience of undecidability' entails. Rather than signalling a withdrawal from politics or a normatively impotent ethics of 'mere openness to the other,' Derrida's account of the experience of undecidability not only points to a fundamental aspect of our basic ethical experience, but also leads to a number of ethico-political demands, which I summarise as the demand to maintain an ethos of interruption.
\end{abstract}

Keywords deconstruction, Derrida, ethics, experience, ordeal, undecidability

In Rogues Derrida breaks off from his account of democracy and, in a lengthy aside, makes his well-known denial of the much-reported ethico-political turn in his later work: 'there never was in the 1980s or 1990s... a political or ethical turn in "deconstruction," at least as not as I experience it'. ${ }^{1}$ While much of the subsequent debate has righty focused on the plausibility of this claim, the qualification at the end strikes me as a little curious; 'experience' seems like an odd word to use in this context. One might have expected 'understand', 'conceive' or 'practice', per-

\footnotetext{
${ }^{1}$ Jacques Derrida, Rogues: Two Essays on Reason, trans. Pascale-Anne Brault and Michael Nass (Stanford: Stanford University Press, 2005), 39. Hereafter cited as $R$.
} 
haps, but 'experience'? The implication seems to be that for Derrida deconstruction is an ethicopolitical experience. In trying to understand what this experience might be, this paper will focus on unpacking a phrase that is both central to understanding Derrida's work and responsible for much of the dissatisfaction with it, namely, the 'experience of undecidability'. ${ }^{2}$

This will require clarifying the concept of experience in Derrida's work-a perilous task no doubt. Addressing what he calls any 'writer reckless enough to use the word', Michael Okenshott warns that ' $[\mathrm{e}] \mathrm{xperience}$ of all the words in the philosophical vocabulary is the most difficult to manage'. ${ }^{3}$ If talking about experience seems a little reckless, then talking about experience in relation to Derrida's work may appear to be courting disaster. After all, wasn't it Derrida who warned us in Of Grammatology that the concept of experience is so unwieldy that it is only to be used sous rature (under erasure)? However, Derrida soon lifts this erasure and despite the increasing prominence of this concept in his work, few, it seems, have turned their attention to it. ${ }^{4}$

After outlining the kind of reading that overlooks these aspects of Derrida's work (Section I), I turn to the concept of experience (Section II). Here I try and show that Derrida, from his early work through to his latter work, is engaged in a project of rearticulating the concept of experience and this, overlooked by friends and critics alike, is vital if we are to understand the ethicopolitical demands of deconstruction. I take this up (Section III) by arguing, firstly, that a specific understanding of undecidability as an ordeal is crucially overlooked by most approaches (which limit undecidability to the formal claim that no rule or norm can specify its application in a particular case); secondly, how this relates modes of undecidability to the rearticulation of the con-

\footnotetext{
${ }^{2}$ This paper has benefitted greatly from conversations with David McNeill, Dan Watts and Peter Dews.

${ }^{3}$ Martin Jay, Songs of Experience (Berkeley: University of California Press, 2005), 5.

${ }^{4}$ A helpful work here is David Wood, "The Experience of the Ethical” in eds. Richard Kearney and Mark Dooley, Questioning Ethics (London: Routledge, 1999), 105-119. Hereafter cited as QE.
} 
cept of experience; thirdly, how the ordeal of undecidability is the necessary condition for our basic ethical experience of responding justly to the other.

But this does not deal with the 'mere openness' problem: deconstruction seems to demand an openness to the other and this, many have argued, suggests a disabling stance of openness which remains vulnerable to charges of being open to any other. In response to this, I outline a series of injunctions that flow from the reconceived notion of experience of undecidability (Section IV), and here I argue that these injunctions are best thought of not in terms of 'openness to the other' but in terms of maintaining an ethos of interruption. Reconceived in this way, we see that the experience of undecidability does not lead to the 'moralizing and unpalatable stereotype' of mere openness that Derrida feared $(N, 194)$, nor to the impotence in deciding which others to welcome that friends (Ernesto Laclau) and critics (Richard Wolin) suspect.

\section{A Directionless Deconstruction}

Not only is Ernesto Laclau a sensitive reader of Derrida with a long-standing engagement with deconstruction but, as Geoffrey Bennington notes, his work 'is arguably the only political theory as such to have engaged seriously with Derrida's work'. Although Laclau's engagement goes right back to his early work, here I will draw on two later essays where Laclau specifically addresses the question of the ethico-political significance of deconstruction (as opposed to incorporating some of its insights into his own theory of hegemony). ${ }^{6}$

\footnotetext{
${ }^{5}$ Geoffrey Bennington, Interrupting Derrida (London: Routledge, 2000), 198, n. 4. See also John Caputo, Deconstruction in a Nutshell (New York: Fordam University Press, 1997), 175, n.19.

${ }^{6}$ Ernesto Laclau, "The Time is Out of Joint" in Laclau, Emancipation(s) (London: Verso, 1996), 66-86. Hereafter cited as TOJ; Ernesto Laclau, "Deconstruction, Pragmatism, Hegemony" in Deconstruction and Pragmatism, ed. Chantal Mouffe (London: Routledge, 1996), 47-67. Hereafter cited as DPH.
} 
Laclau's reading brings into view two dimensions of deconstruction: the promise as a structural feature of all experience, whose openness to the coming of the other leaves it without content $(T J, 73)$, and the ethico-political injunctions of a 'democracy to come' which Derrida links to the classical notion of emancipation (TJ, 75). While Laclau endorses the former movement, which does away with any teleological eschatology and reveals the terrain of structural undecidability, he is less convinced by the latter move insofar as the classical notion of emancipation — which 'Derrida is not at all prepared to put...into question' $(T J, 75)$-requires the synthesis of a series of contents and is thus 'intimately connected to the teleological eschatology that Derrida is deconstructing' $(T J, 76)$. Summarising this position we can say that the problem that arises for Laclau is the following: how is one to conceive the transition between the contentless openness as a general structure of experience and any emancipatory ethico-political contents? While Laclau is certainly not dismissing the latter, his claim is that they remain incompatible with the former. Derrida seems to want his promise and to keep it. That is to say, he wants both the radical openness of a promise without content and the fulfilled ethico-political contents of the classical emancipatory project (linked to democracy).

For Laclau this problem only arises if one makes the 'illegitimate transition' $(T J, 77)$ from the 'ontological' position of constitutive openness and structural undecidability to an ethico-political injunction that necessarily commits one to a particular ethico-political orientation. 'Undecidability', argues Laclau, 'should be literally taken as that condition from which no course of action necessarily follows. This means that we should not make it the source of any concrete decision in the ethical or political sphere' (TJ, 78). However, unlike critics who make a similar point (such 
as Thomas McCarthy and Nancy Fraser), ${ }^{7}$ Laclau does insist that deconstruction has 'important consequences for both ethics and politics' $(T J, 78)$. Deconstruction, according to Laclau, 'makes possible a crucial turn in Political Theory' $(\mathrm{DPH}, 48)$, and it does so by showing that the political is the instituting moment of society, a contingent act not predetermined by some underlying logic. And the flip side of this politico-discursive production of the social is that society remains structurally incomplete because ultimately no contingent act of institution is fully achievable. It remains undecidable. Borrowing Husserlian language, we can say that by widening the field of structural undecidability deconstruction reactivates the contingent moment of decision that underlies any sedimented set of social relations, thus clearing the way for further political decisions. $^{8}$ As Laclau puts it:

Deconstruction is primarily a political logic in the sense that, by showing the structural undecidability of increasingly larger areas of the social, it also expands the area of operation of the various moments of political institution.

\footnotetext{
${ }^{7}$ See Thomas McCarthy “The Politics of the Ineffable: Derrida’s Deconstructionism” in McCarthy Ideals and Illusions: On Reconstruction and Deconstruction in Critical Theory (Cambridge MA.: MIT Press, 1991), 97-119; Nancy Fraser, “The Force of Law: Metaphysical or Political?” Cardozo Law Review 13 (1991), 1325-1331.

${ }^{8}$ Although Laclau is a sensitive reader of Derrida - indeed this is one of the reasons for focusing on his accounthe tends to refer to undecidability in these structural terms and this leads to the actual experience of undecidability (the ordeal) dropping out of view (even where explicit reference is made to the experience of undecidability). But without this dimension we miss a crucial aspect of Derrida's account. Similarly Noah Horwitz, another excellent reader of Derrida, also tends to refer to structural undecidability with the result that our attention is moved away from trying to understand the experience of undecidability. See his "Derrida and the Aporia of the Political, or the Theologico-Political Dimension of Deconstruction," Research in Phenomenology, 32 (2002): 157-176.
} 
However, Laclau is quick to add a sobering note to those wishing to get a political message out of deconstruction. The above quote continues:

This does not imply that...one can derive, from deconstructionist premises, a decision about concrete political arrangements in a particular situation...Theoretical and political arguments that take deconstruction as their starting point can go in many directions $(\mathrm{DPH}, 58)$.

By widening the terrain of structural undecidability deconstruction does not furnish one with any particular ethico-political guidance but for Laclau it does provide us with 'one of the most powerful tools at hand for thinking strategically' (TJ, 81-82).

We can summarise Laclau's position in the following way: Derrida's talk of an openness to the other that is inscribed within the very structure of experience leaves it without determinable content. This is good news because (i) it does away with all teleology and eschatology and (ii) it reactivates the contingency of sedimented practices and thereby extends the terrain of structural undecidability to larger areas of social relations. Precisely because undecidability is inherent in constitutive openness, however, the kind of political moves that take place on this undecidable terrain cannot be determined by any ethico-political injunction. Therefore from deconstruction one cannot derive any ethico-political injunctions. Deconstruction leaves the field wide open.

As lucid as Laclau's argument is, I will try and show that this reading of deconstruction fails to appreciate the significance of the concept of experience in Derrida's work and overlooks Derrida's insistence on the 'ordeal' of undecidability. As we will see, sensitivity to these two aspects of Derrida's account leads to an understanding of 'experience of undecidability' from which a number of ethico-political injunctions emerge. 


\section{Reactivating the Concept of Experience}

Before we begin, however, a doubt may be raised about the very appeal to the concept of experience. Surely for Derrida the concept of 'experience' is a thoroughly metaphysical concept and one he would be reluctant to appeal to determined as it is by the theme of presence. In Of Grammatology, for example, Derrida writes,

As for the concept of experience, it is most unwieldy here...it belongs to the history of metaphysics and we can only use it under erasure (sous rature). 'Experience' has always designated the relationship with a presence. ${ }^{9}$

And similarly in "Violence and Metaphysics" he asks,

Has not the concept of experience always been determined by the metaphysics of presence? Is not experience always an encountering of irreducible presence? ${ }^{10}$

This seems to be particularly bad news for any account of Derrida's work that seeks to emphasise the concept of experience. Indeed, isn't this proposed reading of deconstruction yet another symptom of the very disease that Derrida is so keen to diagnose? And yet in his later work Derrida seems to emphasise 'experience' with great abandon, whether it is 'the experience of the aporia' 'the experience of the perhaps', 'the experience of what happens unforeseeably' or even

\footnotetext{
${ }^{9}$ Jacques Derrida, Of Grammatology, trans. Gayatri Chakravotry Spivak (Delhi: Motilal Banarsidass Publishers, 2002), 60. Hereafter cited as $O G$.

${ }^{10}$ Jacques Derrida, Writing and Difference, trans. Alan Bass (London: Routledge, 2001), 190. Hereafter cited as WD.
} 
'the necessity of experience itself'. ${ }^{11}$ What is Derrida up to here? Why does he lift the sous rature from the 'unwieldy' concept of experience? Why does he not only allow experience to go out without being escorted by quote marks, but to stride around in italics? What happened to the metaphysics of presence and the discipline of quote marks that was demanded in response? In short, how does Derrida get from the 'torturous prudence' of his earlier work ${ }^{12}$ to the claim that '[a]s for some philosophy of "mine"...I prefer to speak of experience'. ${ }^{13}$

Despite appearances, this emphasis on experience in the latter work is not some sudden leap or abrupt about-face but rather a rearticulation of an alternative concept of experience. When Derrida opts for the word 'experience' to describe his own work he crucially adds '[t]he word experience, once dusted off and reactivated a little, so to speak, is perhaps the one I would choose'(Ps, 207). This dusting off and reactivating, I want to claim, is already under way in the earlier work. That is to say, experience under erasure was never the whole story.

We can get a better understanding of this if we take a brief detour into Derrida's engagement with Husserl, for it is in response to the phenomenological attempt to uncover the universal form of experience, or the transcendentality of what Husserl terms the 'living present', that Derrida will suspect the concept of experience of failing to take into account the movement of différance and participating in the reduction of the trace. But at the very moment when Derrida raises this

\footnotetext{
${ }^{11}$ These references are from: Jacques Derrida, Aporias, trans. Thomas Dutoit (California: Stanford University Press, 1993), 5. Hereafter cited as AP; Jacques Derrida, Politics of Friendship, trans. George Collins (London: Verso, 1997), 67. Hereafter cited as PF; Jacques Derrida, Psyche: Inventions of the Other, Vol. 1 (California: Stanford, 2007), 349; $A P$, 19. Such phrases appear right across Derrida's later works, with 'experience' invariably in italics.

${ }^{12}$ This is how Derrida describes Heidegger's earlier caution with quote marks. See Jacques Derrida, Of Spirit, trans. Geoffrey Bennington and Rachel Bowlby (Chicago: University of Chicago Press, 1987), 32.

${ }^{13}$ Jacques Derrida, Points ... Interviews 1974-1999 (Stanford: Stanford University Press, 1995), 363. Hereafter cited as $P s$. This is far from being an off-the-cuff remark. See, $A P, 15 ; N, 192,352,362 ; P F, 105 ; P s, 207 ; S M, 35,65,90$.
} 
suspicion against the concept of experience a 'to the extent that' introduces an opening in which the possibility/promise of an alternative concept of experience can already be heard:

To the extent that the concept of experience in general — and of transcendental experience, in Husserl in particular-remains governed by the theme of presence it participates in the movement of the reduction of the trace (OG, 61-2 - my emphasis).

Despite this suspicion, the possibility of another concept of experience, opened up by this 'to the extent that', begins to emerge in Derrida's early work, a rearticulated concept of experience that Derrida will call 'experience as arche-writing'. Exploring Derrida's engagement with Husserl no doubt raises a host of issues, but what I want to focus on is the way in which it enables one to see the transformation of the concept of experience that Derrida is attempting to bring about. ${ }^{14}$

\footnotetext{
${ }^{14}$ That is to say, it is not my concern here to assess Derrida's reading of Husserl—which would go far beyond the scope of the present discussion — but rather to try and clarify the concept of experience that emerges from Derrida's engagement with Husserl. For a fuller discussion of Derrida's reading of Husserl, see, inter alia, John Caputo, "The Economy of Signs in Husserl and Derrida," in Deconstruction and Philosophy: The Texts of Jacques Derrida, ed. John Sallis (Chicago: University of Chicago Press, 1987), 99-113; Kevin Mulligan "How Not to Read: Derrida on Husserl," Topoi, 10 (1991): 199-208; Mckenna and Evans eds., Derrida and Phenomenology (Dordrecht: Klewer Academic Press, 1995); Lenard Lawlor, Derrida and Husserl: The Basic Problems of Phenomenology (Indiana University Press, 2002); Timothy Mooney, "How to Read Once Again: Derrida on Husserl," Philosophy Today, 47 (2003): 305-321; 'Husserl and Derrida Special Issue' Journal of the British Society for Phenomenology, 36 (2005); Schwab "The Fate of Phenomenology in Deconstruction: Derrida and Husserl," Inquiry, 49(2006): 353-379.
} 


\section{Experience as arche-writing}

Although Derrida is suspicious of the concept of experience, he is equally suspicious of what he calls the "“naïve" critiques of experience' $(O G, 60)$. There is no suggestion of simply dropping this concept but rather of rearticulating it. And if one is going to do so then, as he will say later, the 'word experience itself would have to refer to another concept' $(P F, 67)$. However, this is already underway in Derrida's earlier work. Some eleven lines after telling us in $O G$ that 'the concept of experience... belongs to the metaphysics of presence and we can only use it under erasure' Derrida refers, without quotation marks and under no erasure, to 'experience as archewriting' $(O G, 60-1)$. Arche-writing is a 'new concept' that Derrida introduces five pages earlier, linking it to a 'formidable difference...that 'breache[s] living speech from within and from the very beginning [my emphasis]'. And he goes on to add that 'difference cannot be thought without the trace' $(O G, 56-7)$. Before we outline just what is at stake in Derrida's notion of archewriting, we can already see that 'experience as arche-writing' is referring 'experience' to another concept, a concept that seeks to reveal within the metaphysics of presence difference and temporalization $(O G, 60)$ such that it would breach the immediacy of any self-relation or pure presence, not as some belated empirical accident from without but 'from within and from the very beginning'.

We will see shortly why Derrida thinks this is so, however, we can anticipate this a little if we focus for a moment on 'arche-writing' and ask ourselves why Derrida chooses this term. What work is it doing? By referring experience to arche-writing Derrida is seeking to generalise the difference, mediation and non-presence associated with writing (in the narrow sense) to the possibility of any appearing or presenting as such. That is to say, by rearticulating experience as arche-writing Derrida is going to argue that all experience is in fact conditioned by those very features that are seen as characterising writing. The 'writing' in arche-writing refers us to this dif- 
ference and non-presence, while the 'arche' seeks to emphasise that these are not derivative of some pure presence but are in fact 'originary'. This is clear from the 1968 essay 'Différance' where Derrida introduces arche-writing through a discussion of signification:

the movement of signification is possible only if each so-called 'present' element...appearing on the scene of presence, is related to something other than itself, thereby keeping within itself the mark of the past element, and already letting itself be vitiated by the mark of its relation to the future element, this trace being related no less to what is called the future to what is called the past, and constituting what is called the present by means of this very relation to what is not...An interval must separate the present form what it is in order to be itself, but this interval that constitutes it as present must, by the same token, divide the present in and of itself, thereby also dividing, along with the present, everything that is thought on the basis of the present...And it is this constitution of the present, as an 'originary' and irreducibly synthesis of marks...that I propose to call arche-writing. ${ }^{15}$

These themes will be explored shortly when we take up the discussion of Husserl, but what I want to highlight here is the move Derrida is making with the introduction of arche-writing: it is an attempt to show that the difference and non-presence associated with writing in fact conditions every experience 'from the beginning'. In making this 'experience as arche-writing' move, Derrida is claiming that difference and non-presence are not to be understood as a modification of a simple presence but as that through which presence itself appears.

\footnotetext{
${ }^{15}$ Jacques Derrida, Margins of Philosophy, trans. Alan Bass (Hertfordshire: Harvester Wheatsheaf, 1982), 13. Hereafter cited as $M$.
} 
In Speech and Phenomena the rearticulation of experience as arche-writing attempts to bring out or 'make appear' an 'irreducible nonpresence... or nonself-belonging of the living present'. ${ }^{16}$ It will not be a question of rejecting experience or dismissing presence but a mutual rearticulation and transformation of both that will help us 'recognise' the 'irreducible void' of nonpresence 'on the basis of which the security of presence is decided and raised up'. ${ }^{17}$ What Derrida is concerned with here is to bring before us or make appear the point of insecurity within metaphysics, where the discourse of presence can no longer assure itself of its possibility. Anticipating things a little, we can say that $S P$ would be concerned with, among other things, an experience that would make appear the 'nonpresence and difference at the heart of self-presence' $(S P, 15) \cdot{ }^{18}$

Leaving aside the question of whether one could in fact recognise nonpresence or make it appear, we can see Derrida trying to bring out this point of insecurity when discussing Husserl's claim that in the silent soliloquy of inner life we do not communicate or indicate anything to ourselves for our meaning-acts and expressions 'are themselves experienced by us at that very moment' (cited $S P, 49$ ). Here Husserl is attempting to exclude from the inner monologue of solitary mental life mediation, alterity, difference, nonpresence-in short all that is implied by the term 'indication'-in order to hold on to the unmediated self-presence of lived-experience which assures the purity of ideality and secures the inner certitude of transcendental experience. By arguing that the sign is always already caught up in a structure of repetition and representation, which is not a reduplication that befalls a simple presence but is itself primordial ( $S P, 7 \mathrm{n} .6)$, and that

\footnotetext{
${ }^{16}$ Jacques Derrida, Speech and Phenomena, trans. David B. Alison (Evanston: Northwestern University Press, 1973), 7. Hereafter cited as $S P$.

${ }^{17}$ I have gone with Lawlor's translation of this passage. See Derrida and Husserl, 173.

${ }^{18}$ Ibid., 172-173.
} 
the 'very moment' of the 'now' of the living present is composed 'essentially and indispensably' with the 'not-now' of retention and protention $(S P, 64)$, Derrida is attempting to show that the self-presence of the living present, the identity of experience instantaneously present to itself, does not happen to be contingently affected by difference and nonpresence but is constituted through them.

This irreducible interweaving of the now and not-now, this 'dialectic' of presence and nonpresence, 'open[s] up living to difference, and constitutue[s], in the pure immanence of experience, the divergence involved in indicative communication and even signification in general' (SP 69). What begins to 'appear' is a concept of experience which cannot be thought on the basis of a simple self-presence or self-identity but as emerging through the trace-structure of representation and the movement of différance it introduces — what Derrida calls, '[t]his archewriting' $(S P, 85)$.

This reference to arche-writing, echoing the 'experience as arche-writing' remark in $O G$, should not mislead one into thinking that Derrida is concerned only with the system of linguistic differences and traces. If this were the case one would still be faced with the question that Derrida himself raises in the essay "Différance": 'But can one not conceive of a presence, and of a presence to itself of the subject before speech and signs, a presence to itself of the subject in a silent and intuitive consciousness?' $(M, 16)$ In response Derrida insists that 'this arche-writing is at work at the origin of sense' $(S P, 85)$. Derrida's point here is not simply that the speaking subject—whether it be in dialogue with an other or the inner discourse with oneself—could not be present to itself without inscribing itself within a system of linguistic differences or indicative detours, but the deeper point that the presence to itself of the subject, the self-identity of living consciousness itself, emerges through the movement of the trace and differance and not the reverse. 'This movement of différance,' writes Derrida, 'is not something that happens to a tran- 
scendental subject; it produces a subject' $(S P, 82)$. While experience would be impossible outside the form of presence, presence itself is constituted through the trace structure and the movement of différance. The experience of presence and self-identity would thus be an experience of the trace and alterity. This 'irreducible void,' as Derrida referred to it above, is nothing other than arche-writing:

it is this constitution of the present, as an 'originary' and irreducibly nonsimple (and therefore, stricto sensu nonoriginary) synthesis or marks, or traces of retentions and protentions...that I propose to call arche-writing... or différance $(M, 16)$.

In the formulation 'experience as arche-writing' we can recognise an attempt to make appear 'an irreducible non-presence or nonself-belonging of the living present' $(S P, 6)$, the divergence of the movement of différance that opens up the pure immanence of experience to reveal the alterity 'at the heart of self-presence' $(S P, 15)$.

\section{Experience as interruption}

This rearticulation of the concept of experience opens up the way for Derrida to re-deploy this concept in the latter work. No longer understood simply in terms of a metaphysics of presence, 'experience' now comes to be understood as that which opens up the security of self-sameness and self-identity to the insecurity of difference and alterity. No longer requiring the constraints of quote marks, experience now comes to be understood as a passage to those undecidable moments variously described as 'the aporia', 'the impossible', 'the perhaps', 'the event' and so forth (AP, 19). What I want to focus on here is what I am going to call 'experience as interruption'. 
We can begin to approach this by picking up a remark from one of Derrida's later essays where he rather bluntly writes: 'The event ought to happen to someone... who is thus affected by it...No event without experience (and this is basically what 'experience' means)' ${ }^{19}$ Experience is here linked to the event which happens to a subject and affects that subject. The passive language is not by chance for what it emphasises is the unforeseeable arriving of the event that interrupts the order of what is presently possible, familiar, and under the mastery of a subject. This is an interruption that happens to a subject, beyond its control and mastery.

Before we begin to approach this 'experience as interruption' something must be said about the notion of interruption, for talk of interruption, of 'happening to', would seem to presuppose an already existing subject present to itself and this was something that the rearticulation of experience as arche-writing sought to question. Hence we need to get clear about the order of priority. To recall, what experience as arche-writing seeks to show is that just as there is no linguistic meaning without the indicative detour through the mediation of the sign, likewise there is no subjectivity, no self-relation, without the movement of différance. As Derrida puts it:

The movement of différance is not something that happens to a transcendental subject; it produces a subject. Auto-affection is not a modality of experience that characterizes a being that would already be itself (autos). It produces sameness as self-relation within selfdifference; it produces sameness as the non-identical $(S P, 82)$.

That is to say, difference and non-presence do not come to befall some pre-existing subject relating to itself in a pure auto-affection; rather subjectivity issues forth through the spacing and tem-

\footnotetext{
${ }^{19}$ Jacques Derrida, Without Alibi, trans. Peggy Kamuf, (California: Stanford University Press 2002), 72. Hereafter cited as WA.
} 
porisation that opens up the experience of auto-affection. Experience as interruption needs to be understood as part of this story.

Derrida's reactivation of the concept of experience, in terms of experience as arche-writing, attempts to make appear the constitutive difference and nonself-belonging at the heart of selfidentity. But this attempt to 'make appear' involves the attempt to show that the alterity within self-presence does not appear. As Derrida emphasises, '[a]1l the concepts of metaphysics...cover up the strange "movement" of this difference' $(S P, 85 ; O G, 43,166)$. Through the concept of pure auto-affection, for example, the immediate presence to itself of the subject is taken as a primordial starting point and what this covers over is that subjectivity is itself an effect of the movement of différance: 'the order of subjectivity belongs...to the order of the constituted' as Derrida puts it (SP, 84, n.9). 'Experience as interruption', then, is to be understood as an interruption of the assurance of a subject that takes itself to be immediately given to itself in a pure interiority of ownness. It is an interruption in the sense that it makes appear the more 'originary' experience as arche-writing, revealing the subject's dependency on difference, mediation, the outside world; in short, my irreducible exposure to who or what is other. It is precisely this vulnerability to the who or what is other that will prompt Derrida to describe this experience-as-theevent-that-interrupts as 'traumatic'. 20

\footnotetext{
${ }^{20}$ Jacques Derrida, "Force of Law: The 'Mystical Foundation of Authority," in Deconstruction and the Possibility of Justice, eds. D. Cornell, M. Rosenfeld, \& D. Carlson (London: Routledge, 1992), 3-67, at 27. Hereafter cited as $F L$. Reference to this traumatic relation is made right across Derrida's work. See inter alia, Spectres of Marx, trans. P. Kamuf (London: Routledge, 1994), 127. Hereafter cited SM; Gift of Death trans. David Wills, (Chicago: University of Chicago Press, 1996), 5. Hereafter cited GD; For what Tomorrow Brings, trans. Jeff Fort (Stanford: Stanford University Press 2004), 52-3. Hereafter cited as FWT; Ps, 362; WA, 241.
} 
We can begin to understand this traumatic interruption by looking at David Wood's $Q E$. In an insightful argument that goes via Heidegger's thinking of ethics as a dwelling that preserves (and this notion of preserving will become very important) the disruptive experience of the unfamiliar in the familiar, Wood sees Derrida as reworking this account through an understanding of experience as that which interrupts the domesticated at-homeness and mastery of the subject. This interruption is experienced through the unforeseeable visitation of the arrivant (the arriving of who/what is other) and, although Wood does not refer to it in these terms, the way he describes this interruption does capture precisely what we have been emphasising: 'an experience in which the forces of difference constitutive of any...identity or presence are activated and acknowledged' $(Q E, 52) .^{21}$ Having followed the rearticulation of the concept of experience (as archewriting) through his engagement with Husserl, we can now see what this reactivation involves. What is reactivated through this 'experience as interruption' is the constitutive difference and nonself-belonging at the heart of self-identity, the 'experience as arche-writing' that is concealed beneath the security of self-presence. Through this experience as interruption the unfamiliar erupts into the domain of the familiar, soliciting $(M, 21)$ the domesticated security and athomeness of the subject. It is for this reason that Derrida writes: 'An event [and here we can now read experience] is always traumatic' $(W A, 136)$.

Although we do not get any phenomenological account of experience as interruption, in the way, for example, that we do get a phenomenological description of experience as arche-writing in Derrida's discussion of hearing oneself speak (SP, chapter 6), this reference to 'traumatic' may point the way a little. Pausing for a moment to see what this might entail will prove useful in bringing out what many readings of Derrida, and Laclau's in particular, seem to pass over.

\footnotetext{
${ }^{21}$ I will address the question concerning the relation between activation and acknowledgement below.
} 
At first sight this reference to trauma may seem a little odd, yet it is one that Derrida returns to. It is repeated a little later when, discussing Paul de Man's association of the unforseeability of the event with the suffering of the subject, Derrida goes on to radicalise de Man's point:

By reason of the unforseeability, this irreducible and inappropriable exteriority for the subject of experience, every event as such is traumatic. Even an event experienced as a 'happy' one ...An event is traumatic or it does not happen $(W A, 159)$.

No doubt this is a rather idiosyncratic use of the word 'trauma' - one can hardly imagine a 'happy' trauma. One way of understanding Derrida's generalising of 'trauma' is to see it as an attempt to bring out the sense in which for an event to arrive one must be exposed to some outside, vulnerable to an unforeseeable arriving ( $W A, 159 ; P F 68 ; R, 152 ; A P, 12)$ that is beyond one's control or mastery, such that the subject of this experience is affected or-betterdisturbed. In 'disturb' one can hear not only interruption but also dispossession ${ }^{22}$ and in both a relation to an outside, to the coming of a who or what, is implied. Saying that an event is traumatic in that it disturbs is to suggest an experience of interruption and dispossession, an arriving that throws into disorder (disturbāre) my subjectivity.

Understood in terms of the disturbing arrival of an inappropriable other, one can, perhaps, make sense of a 'happy' trauma: ‘[w]hen love arrives for example...one is exposed' writes Derrida $(F W T, 60)$. Although the context in which Derrida says this is not related to the issue we are focusing on here, I think the experience of love can help make sense of Derrida's use of traumatic. Part of the experience of love is an experience of being disarmed, exposed and disturbed by the other. Here we can turn to a brief passage in David Vellemen's 'Love as Moral Emotions'

${ }^{22}$ disturb, v. 4b. Law. To deprive the peaceful enjoyment or possession of. [OED Online http://dictionary.oed.com] 
where Vellemen points to this being exposed (albeit with differing reasons and for different purposes) in his description of love as that which

arrests our tendencies toward emotional self-protection from another person, tendencies to draw ourselves in and close ourselves off from being affected by him. Love disarms our emotional defenses; it makes us vulnerable to the other. ${ }^{23}$

The philosophical assumptions behind this remark, and the concerns guiding Vellemen here, are very different from Derrida's and the formulation itself would no doubt be questioned by the latter. However, when Vellemen talks of one being 'arrested' or 'disarmed' by this experience, he seems to be pointing to a certain loss of mastery that we have been highlighting. ${ }^{24}$ We can see this by the way in which Vellemen's phenomenological sketch of love changes the perspective through which one approaches this experience, from a perspective which would see love as an impulse or inclination issuing from a subject out toward something, to one where the subject is itself affected by something, taken by surprise and thrown into a state similar to 'amazement or awe'. ${ }^{25}$

Although not expressed in precisely these terms, what Vellemen seems to be describing here is an arriving that not only interrupts a subject (and any attempt to close oneself off from the other), but an arriving that is experienced, if we are to take amazement literally, as a loss of self-

\footnotetext{
${ }^{23}$ David Velleman, "Love as Moral Emotions," Ethics (1999): 38-74, at 361.

${ }^{24}$ Elsewhere Derrida talks of love in terms of 'surrendering one's weapons' and having to 'to give oneself up'. See Derrida, On the Name, trans. by David Wood, John P. Leavey, Jr., and Ian McLeod (Stanford: Stanford University Press, 1995), 74.

${ }^{25}$ Vellemen, 'Love as Moral Emotions', 361.
} 
possession. This switch of perspective (from the active going forth of the subject to the passivity of the arriving of the other) seems to be further underlined when Vellemen maintains that what we ordinarily take to be motives of love are in fact the 'independent responses that love merely unleashes' (one must recall that for Derrida the other is the who or what arrives). Hence love 'lays us open' not only to feelings of attraction and sympathy but also hurt and resentment. This laying open and unleashing suggest an experience of arriving and vulnerability, a disturbing of the self that is beyond the mastery of the subject. As Iris Murdoch put it, with the arrival of love 'the centre of significance is suddenly ripped out of the self' and one 'is shocked into an awareness of an entirely separate reality'. ${ }^{26}$ In other words, love is a 'traumatic' experience.

Trauma, understood in this way, would not refer to the particular contents of an event; it would not name a particular effect of a particular cause, but the very being-exposed/disturbed of the subject of this experience. When Derrida talks of the experience of love as one where the other...disturbs or effects my own property, my own relation to myself ${ }^{27}$ it is not particular unhappy experiences of love that make this disturbing traumatic - the pain and despair that love may bring with it for example — but the fact the one is exposed, vulnerable, 'without protection' $(A P, 12)$ to disturbance as such $(F W T, 58)$. Here one could be 'happily vulnerable' $(F W T, 53)$. The 'trauma' of experience as interruption, then, can be understood in terms of this beingexposed/vulnerable to a disturbance beyond one's control or mastery.

Having fleshed out experience as interruption a little, we see that although it may initially suggest a pre-existing subject in an undisturbed realm of interiority which subsequently comes to be affected by an external difference, it is better understood as that which interrupts the security of

\footnotetext{
${ }^{26}$ Iris Murdoch, Fire and the Sun, (Oxford: Clarendon, 1977), 36.

${ }^{27}$ Jacques Derrida, "Perhaps or Maybe”, in Warwick Journal of Philosophy 6 (1997), 1-18, at 25. Hereafter cited as $P M$.
} 
self-presence and 'makes appear' the constitutive difference at the heart of self-identity. Or to phrase it slightly differently, experience as interruption reveals a subject that is always already interrupted and forever exposed to a 'traumatic' arriving.

If we have interpreted this rearticulated concept of experience (as arche-writing/interruption) correctly, we may still ask ourselves, what follows from this reactivation? Above we picked up Wood's suggestion that the significance of this lay in the activation and acknowledgement of the constitutive difference at the heart of self-identity, and it is here that we can begin to see the stakes involved. I take Derrida's earlier work to involve the attempt to activate this constitutive difference through experience as arche-writing, while I take his later work, on what we have called experience as interruption, to be an attempt to bring about an acknowledgement of this difference that is in some way transformative. That is to say, the acknowledgement of this constitutive difference would not be momentary but rather something that remains. Acknowledgement would involve what Wood describes as the formation of 'certain complex dispositions, ways of remembering, bearing witness to...the significance of such experience' $(Q E, 116){ }^{28}$ This is a crucial observation and something that is overlooked in the kind of reading Laclau offers. In his focus on structural undecidability, Laclau misses the importance of Derrida's rearticulation of experience. Once we understand this rearticulation of experience, however, we can no longer think of the 'experience of undecidability' as merely a structural moment that makes way for the decision that follows.

\footnotetext{
${ }^{28}$ I will say more about this in Section IV below.
} 


\section{Understanding Undecidabilty}

So far I have outlined Derrida's rearticulation of 'experience' and have interpreted this in terms of an attempt to (a) reactivate the nonself-belonging and alterity at the heart of self-presence through the rearticulation of experience as arche-writing, and (b) to make this 'formidable difference' appear through the disturbing arriving of the other, understood in terms of experience as interruption. In this section I want to look at the concept of undecidability and show, firstly, that a specific understanding of undecidability as an 'ordeal' is crucially overlooked by most readings of Derrida; secondly, how this relates modes of undecidability to the rearticulation of the concept of experience; thirdly, how the ordeal of undecidability is the necessary condition for responding justly to the other. This may not seem immediately obvious if we understand undecidability to be limited to the claim that no rule or norm can specify its application in a particular case. No doubt this is part of what undecidabilty refers to, but, as I hope to show, if we remain here we miss a crucial aspect of Derrida's account, namely, his insistence that undecidability is an aporetic experience, an 'ordeal' that one must go through ( FL, 24; GD, 5; SM, 75; WA, 241)

\section{Undecidability as a formal moment of any decision.}

Although often taken to imply an oscillating indecisiveness or paralysing uncertainty, undecidability figures in Derrida's work as part of an analysis of the concept of decision. Rather than being something that is opposed to the taking of a decision, undecidability emerges as the condition of any decision. For our purposes here, however, I am not going to explore the radical version of this account in any great detail but will instead focus on how Derrida brings it to bear on ethicopolitical decisions.

In the essay "Force of Law" one of the things that Derrida seeks to show is that the relation between law and justice is undecidable because the "the decision between just and unjust is never 
insured by a rule' $(F L, 16)$. If a decision were insured by a pre-existing rule that one merely applies in a given situation, then, for Derrida, we might say that such a decision is legal, that it conforms to law, but not that it is just. For a decision to be a just decision there must be a moment where there is an 'épokhè of the rule' $(F L, 22)$, a moment where the law is suspended and a 'fresh judgement' that 're-invents' the law emerges $(F L, 17,23)$.

Part of the reason why Derrida thinks this is so emerges from his more general account of decision and we can summarise the move as follows. Insofar as being just/unjust or exercising justice presupposes freedom and responsibility (for my actions, decisions, etc. [FL, 22-3]) a just decision must exceed the order of the calculable. Why? Because a decision that would be calculable, that is to say, a decision that would determined by the application of pre-existing rule offering guarantees and assurances so that I would know what is to be done in a given situation (do $\mathrm{x}$ to cause y), 'would not be, in the rigorous sense of the term, an act of responsibility or freedom ${ }^{29}$ but the 'unfolding of a programme' $(P M, 20)$ or the 'effecting of a calculation' $(F L, 23)$. And given that a decision presupposes freedom and responsibility, and given that the latter would be incompatible with the mere application of a rule or norm, for there to be a decision there must be a moment that is discontinuous with the order of the calculable. As Derrida puts it:

If I know what is to be done, if my theoretical analysis of the situation shows me what is to be done...then there is no moment of decision, simply the application of a body of knowledge, of, at the very least, a rule or norm. For there to be a decision, the decision must be heterogeneous to knowledge as such... otherwise, there is no responsibility $(N, 231)$.

\footnotetext{
${ }^{29}$ Jacques Derrida, Negotiations: Interventions and Interviews, 1971-2001 (Stanford: Stanford University Press, 2002), 200. Hereafter cited as $N$.
} 
A similar point is made in the later work. In Rogues for example Derrida writes:

Whenever I have at my disposal a determinate rule, I know what must be done, and as soon as knowledge dictates the law, action follows knowledge as a calculable consequence: one knows what path to take...The decision then no longer decides anything but is made in advance and is thus annulled in advance. ..There is no longer any place for justice or responsibility $(R, 85)$.

If there is to be a decision then there must be a moment where one is no longer following the consequence of some determinate knowledge or rule, a 'leap' that 'takes off...and...frees itself' from any calculable process $(P F, 69)$, for it is here that one's freedom and responsibility is engaged. Such a leap is the 'structurally necessary moment' $(F L, 20)$ of undecidability within the very concept of decision.

But this formal account of undecidability seems to return us back to the structural reading we have been trying to resist. While Derrida is engaged in giving such an account - at various moments he reminds us of this: 'All that I am saying here is nothing but the modest analysis of the concept of decision', an analysis which points to something in 'the very structure of any decision' $(N, 232)$ - his insistence on the 'ordeal' of undecidability seems to go beyond this. It certainly goes beyond the kind of structuralist reading we have been considering for 'ordeal' suggests a trying, protracted experience that one undergoes and this is precisely what the structuralist reading leaves out. We might say that undecidability without the ordeal gives us only half of the story.

If we were to see undecidability simply in terms of this formal account one would be left wondering, 'what's the big ordeal in all of this'? Again Derrida leaves us with work to do here for we 
never get any fully worked out account of what kind of experience 'ordeal' is referring us to. However, a brief look at the way in which Derrida's characterises the moment of decision does suggest that, unlike 'trauma', 'ordeal' is pointing to a difficult experience. There is no happy ordeal. I also hope to show that a particular understanding of undecidability, which is not captured in the formal account, is also suggested.

\section{The ordeal of undecidability}

Derrida tells us that the moment of decision, of making the leap, is an 'anxiety ridden moment' $(F L, 20)$, a 'madness' in which we find ourselves confronted with a 'terrible choice' $(P M, 11)$ and the necessity of having to act in a 'night of non-knowledge and non-rule' $(F L, 26)$. Here, at the 'crossroads of chance and necessity' $(P F, 30)$, we are 'given over in darkness to the exception of singularity without rule' $(P F, 219)$, to a 'test' or 'endurance' $(A P, 19 ; G D, 5)$ where we are 'never at peace' but continually 'haunted' $(P M, 20 ; P F, 219)$ by the possibility that we have gone wrong. Alone in this darkness, faced with decisions 'that I alone will have to answer for' $(G D, 91)$, there are no principles, no system or dialectical story that can conjure away the 'ghost of the undecidable' $(F L, 24)$ and relieve me of this ordeal. Here 'remorse'-understood in the sense of 'never being happy with the decision' - is 'irreducible'. As Derrida rather darkly puts it: 'a decision has to be paid for' $(P M, 23)$.

This is quite a disquieting picture. Is Derrida really offering nothing more than the modest analysis of the concept of decision? Is this the only story that one could tell of the moment of decision? From the formal account of undecidability as the structurally necessary moment of making a leap that breaks with existing laws and rules, must we necessarily undergo a terrible ordeal? Could we not experience this leap as a moment of freedom, where a space opens up for creative acts that break free of determined laws and structures? Indeed, wouldn't this moment of 
deciding without any determining ground be, as Laclau puts it, 'like impersonating God' ( $D H P$, 54-55)? And, if so, there seems to be no reason why this need be an ordeal. The undecidable leap of the decision may well be experienced as an exhilarating moment of freedom, a moment 'we mortal gods' $(D H P, 56)$ relish. To say that a decision requires freedom and responsibility, and that one must exceed the order of the calculable to exercise the latter, only gets us to the claim that a decision requires the undecidable moment of an incalculable leap. Something more is needed for the further claim that such a leap is an ordeal. If we are to make sense of undecidability as an ordeal, we can not remain with the account of undecidability so far outlined. Something more must be going on.

In trying to get clear how the notion of 'ordeal' functions in Derrida's account of undecidability two possibilities offer themselves. The first, more radical claim, would be to say that the 'ordeal' of the undecidable, understood in terms of the kind 'disquieting' experience characterised above, is what any decision must go through. The second, more limited claim, would say that such an ordeal is the condition of not just any decision, but rather any just decision. That is to say, it is only once we enter the zone of a particular kind of decision —ethical, political, etc.,that the undecidability that attends any decision is experienced as an ordeal. Although Derrida at times seems to suggest the former $(F L, 24)$, as far as I can tell he never really offers an argument as to why any (i.e. each and every) decision would be an ordeal. Furthermore, if we were to go down the radical route it would be hard to avoid the charge of 'dramatising our difficulties'.

\footnotetext{
${ }^{30}$ Richard Rorty, "Response to Simon Critchley," in Deconstruction and Pragmatism, ed. Chantal Mouffe (London: Routledge, 1996), 41-46, at 42.
} 
Adapting a remark from Sartre, we wouldn't want to say that whenever I choose between a millefeuille and a chocolate éclair I go through an ordeal. ${ }^{31}$

So it seems there are good reasons to go with the more limited claim and to understand 'ordeal' not as a structurally necessary moment of any decision, but as the necessary experience one goes through when trying to respond justly to the other. If we take the attempt to respond justly to the other as our basic ethical experience, then the ordeal of undecidability would be the condition of such experience. As limited claims go this is pretty far reaching. This would suggest that in order to regard ourselves as ethical agents we must see ourselves through this ordeal of undecidability. More than a mere polemic response to ethical-political surety, Derrida's account of the ordeal of undecidability is seeking to 'make appear' an experience that is not some local imperfection or mistake that we could put right or free ourselves from, but a basic state for an ethical subject. Prior to responding to any problem, one must experience oneself as one who is vulnerable to the aporias revealed by the ordeal for it is this that opens up a space for ethics, what we might call a pre-ethical space of ethics. As Derrida notes: 'we must not hide it [the aporia] from ourselves. I will even venture to say that ethics, politics, and responsibility...will only ever have begun with the experience... of the aporia'. ${ }^{32}$

Returning to the context of the attempt to respond justly to the other, the reason for thinking that the 'ordeal' of undecidability is the necessary experience of any just decision is that justice, according to Derrida, concerns the 'singularity' of irreplaceable lives in a unique situation, a situation that is always different and always in need of a 'fresh judgement'. Such a judgement is

\footnotetext{
${ }^{31}$ 'Obviously I do not mean that whenever I choose between a millefeuille and a chocolate éclair, I choose in anguish'. See Sartre, "Discussion” in Existentialism and Humanism, trans. Philip Mairet (London: Metheun, 1989), 57. 32 Jacques Derrida, The Other Heading, trans. Pascale-Anne Brault and Michael B. Nass (Bloomington: Indiana University Press, 1992), 41. Hereafter cited as $O H$.
} 
one 'which no existing, coded rule can or ought to guarantee absolutely' $(F L, 23)$. If a judge merely follows a rule that guarantees her decision then such a judge would, according to Derrida, be a sort of 'calculating machine' $(F L, 23)$, subsuming cases to the generality of a given law and missing the 'singularity of the decision that has to be made' $(P s, 359)$. Here we would be in the order of the calculable, not the 'irreplaceably singular' $(L I, 148)$ situation of justice. A just decision is, in this sense, incalculable.

Now this might still leave us with an experience of the exhilarating freedom of the incalculable leap referred to above. Indeed, talk of a leap, and especially talk of a leap that "would liberate one' $(N, 181)$, does lend itself to the 'exhilarating freedom' interpretation. If this is what Derrida means then he would seem to have made the same mistake as Kierkegaard's dancer who confuses being able to leap very high with the ability to fly. ${ }^{33}$ While the latter suggests a 'being emancipated from telluric conditions', the former is 'the accomplishment of a being essentially earthly, one who respects the earth's gravitational forces'. Derrida, however, is not assuming the privilege of 'winged creatures' nor the 'inhabitants of the moon'. Although he insists that a just decision demands a leap that exceeds the order of the calculable, he is not suggesting that one simply abandons all rules whatsoever. While we would not describe someone who merely applies pre-existing rules or laws to cases as making a just or responsible decision, neither would we do so, Derrida maintains, if one makes no reference to any law or rule. Exceeding does not equal destroying. A just decision, then, is not one that destroys all rules - it 'is not the absence of rules' $(F L, 26)$ - for in the moment of suspending law or rules what would allow us to call a decision just?

\footnotetext{
${ }^{33}$ Søren Kierkegaard, Concluding Unscientific Postscript, trans. David F. Swenson and Walter Lowrie (New Jersey: Princeton, 1974), 112-13. The subsequent four quotes refer to this passage.
} 
Indeed, the moment of suspension leaves itself open to the threat of the 'the most perverse calculation' and so although a just decision requires a leap that exceeds law and calculation, it simultaneously requires calculation $(F L, 28)$. Thus we are left in a paradoxical position: for a decision to be just it must be both 'regulated and without regulation' ( $F L, 23)$. Responding justly must be without regulation so that the decision that responds to the singular other is not neutralised in advance by the mechanical application of a rule, but it must also be regulated insofar as a just decision must take account of existing laws and rules so as not to be left to arbitrary improvisations that can always be close 'to the worst'. And so 'incalculable justice requires us to calculate' $(F L, 28)$. It is here, in this 'obligation' to calculate the incalculable, that the 'ordeal' of the undecidable is undergone. As Derrida puts it:

The undecidable is not merely the oscillation... between two decisions; it is the experience of that which, though heterogeneous, foreign to the order of the calculable and the rule, is still obligated - it is of obligation that we must speak - to give itself up to the impossible decision, while taking into account of law and rules. A decision that did not go through the ordeal of the undecidable...might be legal; it would not be just ( $F L, 24$, my emphasis)

From this we can see that undecidability is not simply the structural necessity of making a leap that breaks with existing rules or norms, as the formal/structural account assumes. It should also be understood as the ordeal of having to respond to 'antinomic injunctions' $(P s, 359)$ or a 'contradictory obligation' $(P s, 360)$ that we unavoidably experience the moment it is a question of doing justice to the other. Rather than a leap that liberates my possibilities from constraining laws, this understanding of undecidability demands a decision which, in needing to be both regu- 
lated and unregulated, calculable and incalculable, is one we experience as an 'im-possible' decision. $^{34}$ The 'ghosts of departed wisdom ${ }^{35}$ mix with the ghosts of the undecidable.

\section{Justice as the experience of interruption}

So far I have argued that although the formal account of undecidability captures an aspect of undecidability, it fails to make sense of Derrida's repeated insistence on the 'ordeal' of undecidability. I then tried to show that the latter is to be understood as the unavoidable experience of the 'antinomic injunctions' any just decision places on us. Not only does this avoid the more decisionistic interpretations of the leap, but it also follows from the characterisation of justice as concerning the singularity of the other. And it is here that the experience as interruption comes in.

\footnotetext{
${ }^{34}$ Derrida insists that 'im-possibility' is not to be understood negatively: 'For me, the experience of the impossible is not simply the experience of something not given in actuality, not accessible, but something through which a possibility is given' (See Derrida, Deconstruction Engaged, ed. Paul Patton [Sydney: Power Publications, 2001], 64). I think one way of understanding this is to think of impossibility not as a metaphysically robust claim that X cannot be, but as referring to the way in which the possibility of $\mathrm{X}$ reveals itself as beyond the order of the possible or calculable; the possibility of $\mathrm{X}$ appears as im-possible or non-possible (see $N, 358-363$ ). As Derrida puts it in Rogues, the im-possible is what 'must remain (in a nonnegative fashion) foreign to the order of my possibilities...[but it is] not privative' $(R, 84)$. Insofar as a just decision becomes possible only by exceeding such an order, its possibility emerges as im-possible, as beyond the order of my possibilities. We might say that 'doing justice to the other' is only possible if it is experienced as im-possible. If my experience of the demand to do justice to the other was along the lines of 'ok, it's possible for me to do justice in this situation by doing X', then, for Derrida I would be in the calculable order of the possible $(\mathrm{OH}, 45)$ where no just decision can emerge. As Derrida claims: when we deem something as possible 'it means we have already mastered, anticipated, pre-understood' it $(N, 194)$ and this means we miss the singularity of justice.

${ }^{35}$ Thomas Paine, The Rights of Man (London: Penguin, 1985), 197.
} 
To say that justice 'concerns the other' does not capture the disturbing arriving of an interruption that opens up the demands of justice. Justice concerns the other, but not simply a determinable other that could be foreseen and assigned a place in the calculable horizon of generalised norms or rules. Rather, justice is a concern for the singularity of the other and this singularity marks an interruption, an experience of interruption. Commenting on the word justice Derrida writes: 'It is the experience of the other as other' $(N, 105)$. To experience the other as other suggests an experience of interruption, for the 'as other' gestures towards a singularity which exceeds, and so interrupts, the calculations and strategies of my present possibilities. In the experience of the other as other 'something incalculable comes on the scene' ${ }^{36}$ This incalculable something, I suggest, is the coming of the arrivant we have named 'experience as interruption'.

Not only does Derrida maintain that '[a]s soon as justice implies a relation to the other, it supposes an interruption' $(N, 230)$, but he more robustly claims that there would be 'no justice without interruption' $(F W T, 81)$. Without the interruption of an incalculable other we would remain in the ordeal-free order of applying calculable norms and rules. Borrowing a phrase from Habermas, we could say that without interruption we would never be propelled into 'the whirlpool of problematization' through which we experience the pull of the antinomic injunctions of doing justice to the other. The ordeal of undecidability we undergo in experiencing the antinomic injunctions of doing justice to the other is itself opened up through an experience of interruption: no justice without the ordeal of undecidability, no ordeal without 'experience as interruption'.

But if one accepts this account, the question can still be raised: well, what follows from this? What kind of demands, if any, emerge from the experience of undecidability? It is to this that I now turn.

\footnotetext{
${ }^{36}$ Jacques Derrida “The Villanova Roundtable" in Deconstruction in a Nutshell, ed. John Caputo (New York: Fordham University Press, 1997), 17. Hereafter cited as $V R$.
} 


\section{Injunctions}

A good conscience sleeps through thunder ${ }^{37}$

Throughout Derrida's work we see him continually returning to the issue of a good conscience and issuing straightforward injunctions against it. ${ }^{38}$ The clearest example of this is to be found in Aproias where he tells us: 'one must avoid good conscience' $(A P, 19)$. This seems, prima facie, counterintuitive. Would we say that a person who donated what money she could spare each month to Save the Children, or the teenage volunteer who gets up every Saturday morning to help with the meals on wheels service for pensioners, should avoid a good conscience? Aren't these the kind of acts where it is ok to have a good conscience? And if so what does Derrida have against this? We need to take a closer look at what 'having a good conscience' might mean for Derrida and why he thinks we should avoid it.

The $O E D$ explains 'good conscience' as 'a consciousness that one's acts, or one's moral state, are right'. Having a good conscience is a knowing: 'My action was right', 'I fulfilled my obligations', 'I did the just thing'. Having a good conscience implies we are certain about our ethical decisions or state, it assumes that responding justly is something we can be sure about. This, for Derrida, is anything but responsible (see n.40 below). Put polemically, this assurance of a good conscience reassures us that we have assumed and fulfilled our ethical responsibilities, allowing us the peace of a 'sweet sound sleep" ${ }^{39}$ while the thunder continues to shake the world outside.

\footnotetext{
${ }^{37}$ This is slightly adapted from Thomas Fuller's 'A quiet conscience sleeps through thunder' in his Gnomologia, 1732, 374. OED entry for 'conscience'.

${ }^{38} P F, 42 ; S M, 15,28,66,97,233 ; N, 99,103,138,179,232 ; G D, 25,67,85 ; P M, 20 ; O H, 41,45,81 ; A P, 19 ; P s$, 286, $287361 ; D E, 87,101$.

${ }^{39} \mathrm{~J}$. Wilson 'That sweet sound sleep that is the lot o' a gude conscience' in Blackwood Magazine, Apr. 1827, 476. (see $O E D$ entry for conscience).
} 
I say polemically because it seems clear that Derrida is engaged in a polemic. When he moves against the 'moralizing moralists and good consciences who preach to us with assurance' about ethical and political responsibility, when he reminds the 'knights of good conscience' that one cannot avoid or dissolve the conflictual obligation of doing justice to the other, that when it comes to our ethical experience we are all inhabitants of the 'land of Moriah' every second of every day $(G D, 67-69)$, the rhetoric deployed is clearly engaging a polemic against ethical/moral certainty. Similarly, the way in which he characterises the disquieting experience of the ordeal of undecidability seems aimed not merely at giving an analysis of a structural feature, but to reach out and shake the reader. When it comes to our basic ethical experience, Derrida seems to say, we cannot lie in the afternoon sun, shaded by the certainty of rules and norms, and enjoy that sweet sound sleep of a good conscience. Just as he seeks to remind the knights of good conscience that they are in the land of Moriah, so Derrida's characterisation of the ordeal of undecidability seeks to make us see that we are on the high wire, on a thunderous night not of our choosing, subject to the elements, with no light above us and nothing below. The only certainty here seems to be the insomnia of a bad conscience.

While the polemical element is clearly there in Derrida's account, it is not mere polemics. If having a good conscience is to be understood in terms of a knowledge or certainty that assures one that one has fulfilled one's ethical responsibilities, then from the account of the ordeal of undecidability as a necessary condition for responding justly to the other we can see why Derrida thinks having a good conscience is something that must be avoided when it comes to a just or ethical decision. Returning to the context of the injunction against a good conscience cited above, Derrida explains: 
Good conscience as subjective certainty is incompatible with the absolute risk that...every responsible decision... must run. To protect the decision or the responsibility by knowledge, by some theoretical assurance, or by the certainty of being right...is to transform this experience into the deployment of a program, into the technical application of a rule or a norm, or into the subsumption of a determined case ( $A P, 19-$ my emphasis).

Knowing or having certainty about responding justly may reassure one's conscience and that of others but it does so by dissolving the very ordeal (experience) of undecidability through which the possibility of doing justice is given. Without this ordeal, without this experience of the conflictual obligation or antinomic injunctions of justice opened up by the interruption of an incalculable other, 'one might as well give up on...justice' $(S M, 65)$. Behind Derrida's injunction against good conscience is the demand not to dissolve the ordeal of undecidability, not to close off this experience of having to respond, without assurance, to the interruption of an incalculable other.

Before fleshing out this demand a little more I want to respond to a possible objection. Might one not say that although a just decision must 'go through' the ordeal of undecidability, once through the ordeal one can have the kind of certainty of having done the just thing that Derrida denies? Indeed, the very language of 'going through' would seem to suggest an understanding of the ordeal as momentary. On this understanding, knowledge or certainty could be had about our ethical decisions, they could be calculated and determined with complete assurance, it is just that we lack the resources for this (i.e. time, knowledge) beforehand, hence the ordeal. Indeed, Derrida tell us that 'justice...doesn't wait', and he insists that 'a just decision is always required immediately' $(F L, 26)$. Perhaps the ordeal of undecidability emerges because of the empirical limitations we encounter in responding to the urgency of justice with a decision that 'cannot furnish 
itself with infinite information and unlimited knowledge of conditions, rules or hypothetical imperatives' $(F L, 26)$. That is to say, the ordeal of undecidability would be the name for the experience of empirical limitations that we undergo in having to decide with finite resources. There would be nothing to rule out achieving certainty after the decision. And so the good conscience of having responded justly to the other remains compatible with the ordeal of undecidability we experience when trying to decide what would be the just response.

But this would reduce the ordeal of undecidability to the indecisiveness of an empirical moment and this, as we have seen, is what Derrida insists it is not. Derrida has already argued that a just decision cannot fall from a pre-existing rule or norm, or be the consequence of some determinate knowledge, because it is a response to the singularity of the other. So even if we had all resources at out disposal $(F L, 26)$, '[c]enturies of preparatory reflection and theoretical deliberation,' the decision itself, if it is to be a just decision, must not be the consequence of such knowledge for one then applies or unfolds a program. And this, as we have seen, is incompatible with a just decision. As we outlined above, for Derrida a just, ethical or responsible decision presupposes a leap that is discontinuous with the order of knowledge, hence the characterisation of the ordeal as 'acting in the night of non-knowledge and non-rule'. Unlimited resources may help us penetrate this night, but they will not dispel it.

If I could retrospectively dispel this night so that I now know I did the right thing, then this implies that the decision I faced was one with a knowable, correct outcome- - j just needed to calculate it correctly. But if this is the case then the decision slips back into the order of the calculable that justice demanded it break with. What I faced was an incalculability that remained of the order of the calculable but 'escape[d] it for contingent reasons, such as finitude, a limited power, etc' $(F W T, 49)$. The upshot of this account seems to be that at no point can I be certain of the justness of my decision. Hence the haunting and lack of peace: 
That is why the ordeal of the undecidable that...must be gone through...is never past or passed, it is not a surmounted or sublated (aufgenhoben) moment in the decision. The undecidable remains caught, lodged, at least as a ghost—but an essential ghost — in every decision. Its ghostliness deconstructs from within... any certitude...that would assure us of the justice of a decision $(F L, 24)$

The ordeal of undecidability as Derrida understands it, then, cannot be understood as a momentary indetermination that we leave behind; rather it is an experience that remains to disturb any good conscience and keep us ethically off balance. Returning to the context of Derrida's injunction to avoid good conscience, the ordeal of undecidability is something we experience as an 'interminable...remainder' $(A P, 19)$. Our sleep will always be interrupted.

'Not a moment to be...forgotten or suppressed' $(P F, 219)$

Behind the polemics against the 'irresponsibility' of having a good conscience $(P F, 219)^{40}$ and the insistence that '[n]o-one could or should... be quietly reassured about their decisions' (PM, 20) is the demand not to suppress or forget the ordeal of undecidability. As I argued above, the ordeal of undecidability is an experience of a conflictual obligation that emerges from an incalculable interruption that places on me the 'im-possible' demand to do justice to the other as other. This, as we have seen, is an interminable experience and not a passing moment. So what would suppressing or forgetting this ordeal mean?

The former suggests neutralising the ordeal in advance by applying norms in the certainty that the road ahead is clear (here I would not experience the ordeal). The latter suggests dissolving

\footnotetext{
${ }^{40}$ See also $O H, 41,45,81 ; P s, 359,361 ; N, 182,232$
} 
the ordeal with the certainty of having taken the right road (here the 'ordeal' would become a mere contingent moment in a calculable process). In both cases there is no interrupting arrival of the other. Suppressing the ordeal closes off the interruption of the other by transforming the conflictual obligation to respond justly to the other into a technical problem to be solved by the application of a rule or norm. This, in turn, would imply not only missing the 'always unheard of singularity of the decision that needs to be made' $(P s, 360)$, but closing oneself off from the experience of the other as other. Here the other would never arrive. Forgetting the ordeal would do so by transforming the ordeal from an interminable experience that remains to disturb and affect me into a momentary indecisiveness that merely makes way for the decision that follows. Here I would not be affected by the ordeal and so would remain untouched by the other. And this is another way of saying the other does not arrive.

I suggested that the problem with having a good conscience was that it dissolved the ordeal of undecidability, and we can now see that the problem with the latter is that it closes off or denies the arriving of the singular other. Thus the demand not to dissolve the ordeal of undecidability, which I identified as motivating the injunctions against a good conscience, is itself motivated by the demand to remain open to the interruption of the singular other, to experience as interruption. Insofar as closing oneself off from such interruption destroys the possibility of responding justly to the other, the demand to remain open to the arrival of the other would be an ethical demand.

'Openness to the other', however, is probably not the most helpful way of phrasing this demand. Although most of the literature speaks of it in this way it leads to at least two problems. The first is raised by thinkers as different as Laclau and Wolin: openness to the other as a demand suggests a passive stance of openness which remains vulnerable to charges of being open to any other. Laclau, for example, argues that being open to the other regardless of the content of that otherness would appear to be more like ethical nihilism than an ethical injunction $(T J, 70)$. 
Wolin makes a similar point when he deploys the reductio ad Hitler by arguing that there are “others'—neo-Nazis, white supremacists, and other racists - who have forfeited their right to my openness' and this leaves the demand of openness normatively impotent and politically naïve. $^{41}$ While Laclau is unconcerned about this lack of normativity in deconstruction, Wolin is rightly troubled. The second problem, recently put forward by Martin Hägglund, argues that as a constitutive structure of experience 'openness to the other' is unavoidable and therefore it simply makes no sense to make any ethical or normative demands here. As Hägglund puts it, 'openness to the other cannot be an ethical principle since it is not a matter of choice'. ${ }^{42}$

A more promising route for understanding the demands of deconstruction might be to think of it in terms of maintaining the experience of undecidability (as interruption and ordeal) as this avoids the charge of impotence - such maintaining would require closure - and the suspicion that Derrida is trying to derive an ought from an is (or, at the very least, is confusing the two). I will briefly address both of these points, starting with Hägglund's point first.

Hägglund is right to say that openness to the other is not a matter of choice. However, I want to suggest that speaking of an ethical demand here is not incoherent. Although it may appear so, things become a little clearer if we recall that there are (at least) two layers to the structure of experience as Derrida rearticulates it. The first layer, what I called experience as arche-writing, pointed to a constitutive openness to the other in terms of the difference and alterity at the heart of any identity. Here openness to the other is unavoidable for there would be no identity, no selfrelation without it. Hägglund is right insofar as this can not be a matter of choice and therefore it

\footnotetext{
${ }^{41}$ Richard Wolin, The Seduction of Unreason: The Intellectual Romance with Fascism; From Nietzsche to Postmodernism (New Jersey: Princeton University Press, 2004), 223-4.

${ }^{42}$ Martin Hägglund, Radical Atheism: Derrida and the Time Of Life (Stanford: Stanford University Press, 2008), 187.
} 
makes no sense to talk of an ethical demand here. On the second level, however, there is the disturbing arrival of the other that I termed 'experience as interruption'. Now this can be thought of as unavoidable in the sense that, for Derrida, it is the condition of possibility for responsibility, ethical decision and so on. Moreover, it can also be thought of as unavoidable insofar as it reveals or reactivates one's 'traumatic' relation to the other. However, as we have seen, one can forget or suppress it. That is to say, one can choose to deny it. Derrida emphasises this when talking about 'the undeniable, and I underscore undeniable, experience of the alterity of the other' and goes on to explain 'I underscore undeniable to suggest only deniable' $(R, 38)$. Similarly, when Derrida insists that 'we must not hide it [the aporia] from ourselves' $(O H, 41)$ this suggests that we could indeed hide the aporia from ourselves (through suppressing or forgetting the ordeal). Given that the aporia is the ordeal we experience in having to respond to the conflictual obligations placed on us by the interruption of the other, hiding the aporia would be a way of denying the interruption of the other. In this respect it is probably more appropriate to describe this second layer as undeniable rather than unavoidable. So when Derrida insists that one cannot and should not close off the relation to the other, we have to bear in mind both the unavoidable and 'undeniable' layers. Once this is recognised then one can make ethical demands here.

One could avoid the ambiguity that leads to the kind of response from Hägglund if we thought of the demand of deconstruction not so much in terms of 'openness to the other' but rather as the demand to maintain the experience of undecidability (as interruption and ordeal) through which a space is held open for the arriving of the other. This would be a demand not to forget or suppress this experience $(R, 38)$. This demand not to deny this experience but to respond to and remember it would involve, to recall Wood, 'the formation of complex dispositions' that would 'bear witness to' such an experience, not as the memory of a past moment that disappears with the deci- 
sion that follows, but as an experience that remains and leaves one exposed to the interruption of the other.

We could think of this as being called upon to maintain an ethos of interruption. Such an ethos would involve 'cultivating the difference-to-oneself...that constitutes identity' and developing a disposition of openness to the coming of the other, what Derrida describes as a 'culture of oneself $a s$ the culture of the other' $(\mathrm{OH}, 10-11)$. From this we can perhaps glimpse a fourth injunction emerging, one that would orientate the maintaining of such an ethos and demand a commitment to preserving the possibility of the new, the heterogeneous — what we might call a 'fidelity...to the to come' $(R, 4)$.

\section{'Prevent certain things from coming to pass' $(N, 194)$}

By 'to come' I understand experience as interruption, that is, the incalculable arriving of a singular other (and for Derrida the other refers always to who or what comes). This is captured by Derrida's discussion of the event in Rogues — which could equally be applied to the 'to-come'when he talks of an 'incalculable irruption, the singular and exceptional alterity of what...or indeed of who...comes' $(R, 128)$. Understood in this way, the 'to-come' is not referring to the notyet-present of a future arrival or something we can have certainty about; it is not a modality of the present and neither is it of the order of knowledge but - and here is the second dimension to the to-come-instead belongs 'to the time of the promise' $(P F, 306)$. Whether it is of a reason to come $(R, 148)$, a democracy to come $(R, 90-91)$ or a friendship to come $(R, 4)$, each is structured like a promise, never present but always remaining to be thought and re-thought. By 'fidelity to the to-come', then, I understand the duty to remain faithful to the promise, to create the conditions that open up and maintain spaces for the arrival of who or what comes. With this in place we can now address the problem of openness. 
From these brief remarks we begin to see that the injunction to maintain the ordeal of undecidability - understood not in terms of 'openness to the other' but in maintaining an ethos of interruption — need not lead to a passive stance of impotent openness as Laclau and Wolin suspect. For in creating and maintaining the conditions for the arrival of the other, wouldn't such an ethos demand that we prevent the arriving of that which would close off the space for the arriving of the other, that would put an end to the very possibility of any interruption, any culture of the other? Wouldn't it demand of us that we do not remain neutral, that we should, that it is necessary, to do everything possible to prevent certain events/others from arriving? Derrida unambiguously says that indeed we must:

The coming of the event is what cannot and should not be prevented; it is another name for the future itself. This does not mean that it is good-good in itself-for everything and anything to arrive; it is not that one should give up trying to prevent certain things from coming to pass [my emphasis]... But one should only ever oppose events that one thinks will block the future or that bring death with them: events that would put an end to the possibility of the event $(N, 194)$.

Being faithful to the to-come, so that one does not close off the space for the arriving of the other but instead creates the conditions for maintaining such a space, does not mean that one is left open to anything. One's fidelity, one's pledge or promise to maintain such a space itself calls for forms of action, practice and intervention. As Derrida insists, 'a promise must promise to be kept, that is not to remain "spiritual" or "abstract," but to produce events, new effective forms of action, practice, [and] organization' $(S M, 89)$. The affirmation of such an ethos thus requires taking a position; without the latter the former remains spiritual, abstract. Out of a fidelity to the to- 
come one must close off in the face of an arriving that would destroy the very space for the interruption of the other $(N, 25)$. The demand to maintain a space for the arriving of the other thus cannot be reduced to the 'moralizing and unpalatable stereotype' of mere openness that Derrida feared $(N, 194)$, nor the impotence in deciding which others to welcome that Laclau and Wolin suspect. Instead it demands that we calculate in order to prevent the emergence of discourses that close the to-come. ${ }^{43}$

${ }^{43}$ In a footnote (Radical Atheism, 231-2, n. 4) Martin Hägglund has challenged the kind of view that I am trying to defend here. Hägglund acknowledges that '[t]hese passages [i.e. passages where Derrida makes a distinction between open/closed systems] clearly imply an opposition between 'good' systems or actions that are open to the future and 'bad' systems or actions that close down the future.' However Hägglund goes on to maintain that this opposition is 'untenable given the logic of deconstruction.' Hägglund rejects any suggestion of a normative claim here arguing that 'openness to the future is unconditional in the sense that everything (including every system or action) is necessarily is open to the future'. But if this is so then it is hard to make sense of what Derrida is doing here. How can one talk of closed systems if every system is necessarily open? Furthermore, given the necessity of openness normative demands of openness would appear confused at best. Although Derrida is less than clear on this issue, I think there is a way, overlooked by Hägglund, of making sense of this. Derrida identifies these systems not in terms of being closed but rather as systems that 'close and close themselves off from' the coming of the other. That is to say, these systems are marked by a general discourse of closing off, not a state of being closed. That structurally they can never be closed in no way precludes one from speaking of these as systems of closing off. What is crucial here is to appreciate the unavoidable/undeniable layers at work - structurally every system is unavoidably open, but the undeniable layer points to the possibility of systems constructing themselves around denying, suppressing or closing themselves off from this openness. Totalitarian regimes are such systems $(N, 182)$. Democracy, by contrast, is a system structured around openness, however imperfectly realised and despite the alibis of actually existing democracies (for example through the institutionalisation of contestation, debate, interminable self-criticizability, intrinsic historicity and so forth. [See $N, 194 ; R, 25,86-7]$ ). It is at this level that Derrida's distinction between 'good' or 'bad' systems is operating, and once we take this into account then there is no reason why the (necessary) openness of systems renders normative claims against systems or discourses of closing off a non-starter. 
This demand to prevent certain discourses from emerging is taken up in a 1994 roundtable where, in response to a question about the political dangers of too much diversity and what deconstruction has to say in favour of the unity of the community, Derrida responds by noting that while deconstruction is not out to destroy all totality, it does insist on

the heterogeneity, the difference, the dissociation, which is absolutely necessary for the relation to the other. What disrupts totality is the condition for the relation to the other. The privilege granted to unity, to totality...to community as a homogenized whole - this is a danger for responsibility, for decision, for ethics, for politics. That is why I insisted on what prevents unity from closing upon itself, from being closed up ( $V R, 13$ - my emphasis).

What Derrida describes here as a disruption — the heterogeneity, difference, dissociation which makes possible the relation to the other-characterises the ethos of interruption. The reason why the attempt to totalize or gather a community into a homogenized whole would present such a danger is precisely because it would leave no room for the conditions necessary for the coming of the other and, therefore, the very 'possibility of responsibility, of a decision, of ethical commitments' $(V R, 13)$. That is to say, it would deny the experience of undecidability (as interruption and ordeal) and close off the space an ethos of interruption seeks to hold open. And it is for this reason that Derrida does not simply describe this relation to the other which prevents such closure, but, as he notes in the response above, insists upon it. This insistence seems to point beyond a mere neutral description of the structural feature of constitutive openness to a demand, 'an ethical and political duty', $(V R, 14)$ that is made in response to such danger and, therefore, presumably to prevent that danger from emerging. 
Indeed, Derrida will go on in this response to link his insistence on that which prevents closing off with an orientation that prevents totalitarianism, nationalism and egocentrism:

People who fight for their identity must pay attention to the fact that identity is not the selfidentity of a thing... but implies a difference within identity... a culture is different from itself...the person is different from itself. Once you take into account this inner and other difference, then you pay attention to the other and you understand that fighting for you own identity is not exclusive of another identity, is open to another identity. And this prevents totalitarianism, nationalism, egocentrism and so on ( $V R, 13-14-$ my emphasis).

Here we see Derrida pointing to the importance of the two layers of experience we identified in terms of the 'inner' (arche-writing) and 'other difference' (interruption). Derrida seems to be claiming that 'taking into account' these two layers of experience leads to a 'paying attention' and this brings about an 'understanding' that prevents the emergence of certain discourses. My claim here is that 'taking into account' is part of what I have been referring to as maintaining an ethos of interruption; it would answer to the demand not to forget or suppress the experience of undecidability (as interruption and ordeal) but to bear witness to it. This would involve the formation of 'complex dispositions' referred to by Wood, or what Derrida describes as 'cultivating the difference-to-oneself...that constitutes identity' $(\mathrm{OH}, 10-11)$. And it is through the formation or cultivation of such dispositions that this 'taking into account' would reorient one's attending to the other and transform one's understanding of the 'inner and other difference'.

Returning to the injunctions outlined above, we see that while one cannot have a good conscience about one's decisions, and while the ordeal of undecidability must not be dissolved, the demand to hold open a space for the arriving of the other, pace Laclau and Wolin, 'must not be 
the "anything whatsoever"' $(S M, 168)$. For this 'anything whatsoever' harbours behind it 'those too familiar ghosts, the very ones we must practice recognizing' $(S M, 168)$. These are ghosts who bring with them systems that 'close themselves off from the coming of the other' $(N, 182)$. Here, at the very moment when he rejects 'the anything whatsoever' reading of deconstruction, when he demands vigilance with regard to those others who presumably we must not remain open to, Derrida talks of a practice of recognizing. Recognising these others is something we must practice doing. A similar demand is made in $O H$ where Derrida insists that we must anticipate and not simply give ourselves over to the rhetoric of the absolutely new, for under this banner of the absolutely new 'we can fear seeing return the phantoms of the worst'. Thus one 'must' be suspicious of the 'exposure to what would no longer be identifiable at all' and 'learn to identify' these ghosts in all their guises $(\mathrm{OH}, 18,77)$.

Understood in these terms, deconstruction is not an 'anything whatsoever' openness but a complex disposition that seeks to hold open a space for a relation to the other. And in doing so, deconstruction demands that we oppose and attempt to prevent the arrival of that which would close off such a space. 'We must not be open to whatever comes' $(P M, 11)$. That is to say, the ethico-political experience of deconstruction does not remain impotent; it intervenes in order to maintain an ethos of interruption.

\section{Conclusion}

In this paper I have tried to correct the idea that 'the experience of undecidability' refers simply to a structural openness by showing (i) that from the early work through to the later work Derrida has been engaged in an attempt to rearticulate the concept of experience in a way that brings out the difference at the heart of self-presence and our 'traumatic' relation to the other; (ii) that there is a particular understanding of undecidability as an ordeal that (a) is a response to the experience 
of an conflictual obligation and so already situates us in the zone of a particular kind of ethicopolitical decision and (b) is the condition of our basic ethical experience of trying to respond justly to the other; (iii) that experience as interruption is what opens up the ordeal of undecidability and given that such an ordeal is necessary for any just decision, justice would not be possible without such an experience. From this I then tried to show that this account leads to a series of injunctions which I summarised as the demand to maintain an ethos of interruption. Understood in this way, the experience of undecidability, far from signalling a mere structural openness that is ethically impotent and politically naïve, turns out to be a crucial aspect of our most basic ethical experience of doing justice to the other, and one which intervenes in a normatively orientated way. 